\title{
SEISMIC ACTIVITY AND PORE PRESSURE ACROSS ISLAND ARCS OF JAPAN
}

\author{
Naoyuki FujI** and Kei KuRITA** \\ * Department of Earth Sciences, Kobe University, Kobe Japan \\ ** Geophysical Institute, University of Tokyo, Tokyo Japan
}

(Received July 17, 1978; Revised November 6, 1978)

\begin{abstract}
Recent seismic researches have revealed the variation of shallow seismic activity across the trench-arc system of Japan, which is characterized by, A) a high activity throughout the crust and upper mantle between trench axis and "aseismic front", B) a low activity between "aseismic-front" and volcanic front, and C) a moderate activity within the upper crust behind volcanic front. This variation of shallow seismicity across the island arc is explained by the effects of pore pressure in the crust, based on laboratory experiments of stick-slip and stable-sliding movements combined with temperature distribution estimated from terrestrial heat flow and thermal model of subducting slab. High pore pressure is expected in the low activity area (region B). Pore pressure is controlled mainly by 1) fluid supply from below (released from subducting oceanic crust), and 2) permeability distribution in the crust and upper mantle. Dehydration process in subducting slab has a great influence on shallow seismic activity.
\end{abstract}

\section{Introduction}

Among geophysical and geological observations, the spatial distribution of earthquakes is one of the most direct indications of plate interactions. Recent investigations of precise determination of microearthquake foci in the plate convergence regions have revealed some detailed features of the intraplate shallow seismicity (e.g., Orke, 1977; TAKAGr et al., 1977), and interplate seismicity such as the double-planed structure of deep seismic zone (Tsumura, 1973; Umino and Hasegawa, 1975; Engdahl and Scholz, 1977; HasegaWa et al., 1978).

TAKAGI et al. (1977) noted that in the northeast Japan arc, shallow intraplate earthquakes occur behind (i.e., landward of) the volcanic front and are confined in the upper crust having a compressional wave velocity $\left(V_{p}\right)$ of $6.0 \mathrm{~km} / \mathrm{sec}$ (depths less than $20 \mathrm{~km}$ ). In the southwestern part of Japan, Orke (1977) showed that frequency distribution of focal depths has a maximum at $10-15 \mathrm{~km}$ and is mostly confined within the $V_{b}=6.0 \mathrm{~km} / \mathrm{sec}$ layer. Yamashina et al. (1978) pointed out that a low-seismicity region (frontal arc) between the volcanic front and "aseismic front" (YosHrr, 1975) can be observed in various regions in the circum Pacific trench-arc systems. Since this low activity region has a width of $50-100 \mathrm{~km}$, it is called "aseismic belt." Major seismic activity is concentrated in the prismatic region, which is bounded by "aseismic front" and trench axis. We call this region as "seismic prism." Actually these characteristic features are most distinguishable in the northeastern part of Japan (Mogr, 1967), where is one of the most highly investigated areas through microearthquake and crustal deformation observation network of Tohoku University (TAKAGr et al., 1977), and other geophysical observations as discussed by YoshII (1978). 
A shallow earthquake is considered to be the stick-slip sliding instability on a preexisting fault (BYERLEE and BRACE, 1969). Although many difficulties and uncertainties still exist in the application of laboratory experiments on stick-slip and stable-sliding phenomena to the real earth (BRACE, 1972), the microearthquake activity in the crust of trench-arc systems can be understood through these phenomena at least qualitatively. The depth-limit of the occurrence of shallow earthquakes of the San Andreas fault have been tried to be explained by the transition from stick-slip to stable-sliding caused by temperature variation (BRACE and ByerleE, 1970). Stesky and Brace (1973) suggested that existence of fault gauge or high pore pressure could explain the observed low frictional stresses of the San Andreas fault.

In this paper, we try to explain the vertical and horizontal variation of shallow seismic activity across the trench-arc systems by means of the effects of pore pressure on the stickslip to stable-sliding transition for pre-existing fault deduced from laboratory experiments. When we consider the temperature distribution and thermal processes beneath island arcs (e.g., HASEBE et al., 1970; ANDERson et al., 1978), we can infer that variations of pore pressure should be closely related with the water released by the dehydration reaction of subducting oceanic crust (Anderson et al., 1976; Delany and Helgeson, 1978; R.N. Anderson, personal communication, 19.78), andesitic volcanisms (e.g., RINGwoon, 1974; OxBurgh and TurcotTe, 1976; Anderson et al., 1978), and the evolution of frontal arc structure (KARIG, 1974; KARIG and Sharman, 1975).

\section{Cross Sectional Structure and Shallow Seismicity}

Cross sectional distributions (a band about $100 \mathrm{~km}$ wide) of released seismic energy and microearthquake foci across the northeastern part of Japan along $39.5^{\circ} \mathrm{N}$ are shown in Fig. la, $\mathrm{b}$, respectively. In estimating seismic energy ( $E$, in erg) by the use of the relation $\log E=1.5 M+11.8$, the earthquakes that occurred during 17-year period (1960-1976) with focal depths less than $60 \mathrm{~km}$ were selected, whose magnitude $(M)$ were tentatively taken from the Seismological Bulletin of the Japan Meteorological Agency (JMA). The distributions of microearthquake foci (Fig. 1b) were reproduced after TAKAGI et al. (1977) in which data were taken over one and a half years from April, 1975 to October, 1976.

As seen in Fig. la, b, shallow intraplate earthquakes are distributed behind the volcanic front and clearly separated by "aseismic belt." This belt (hereafter called region B) would correspond to the non-volcanic arc or the frontal arc (KARIG, 1974), and its nature of very low seismic activity throughout the crust and upper mantle is clearly identified both in microearthquake foci distribution for one and a half years and in seismic energy release for 17 years. A thick line segment on the top of Fig. Ib indicates the land area, and the accuracy of the location of earthquakes is quite high, about $2 \mathrm{~km}$ in epicenter and less than $3 \mathrm{~km}$ in focal depth at least in and near the land area (HASEGAWA et al., 1978).

Figure 2 shows another example of cross sectional structure of seismic activity in western part of Japan (Kyushu). Data were taken from the Seismological Bulletin of the JMA (1960-1976). The distribution of the seismic energy release and the earthquake foci are similar to that in the northeastern Japan, although the accuracy of the determination of earthquake foci are not so good because of the lack of microearthquake observation network.

The crustal structure derived from explosion seismic observation (Yoshri and Asano, 1972; Research Grout for Explosion SeIsmology, 1977) are also indicated in Fig. 1b. 

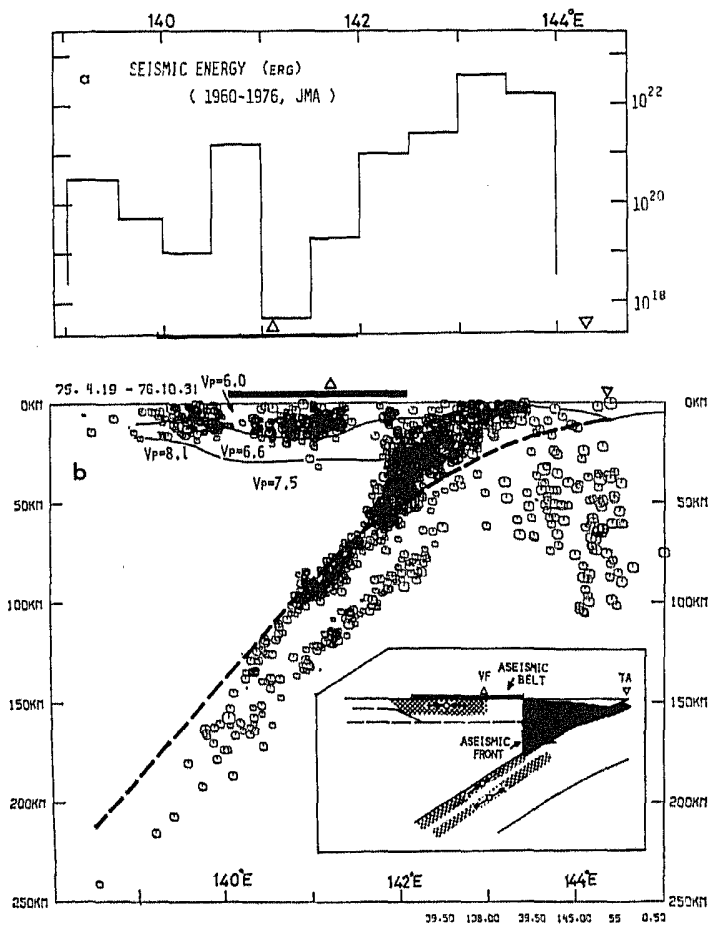

Fig. 1. (a) Cross sectional distributions of released seismic energy along the $1^{\circ}$ wide belt at $39.5^{\circ} \mathrm{N}$, in units of erg summed over 17 years by $1 / 2$ degree interval in the northeastern Japan. Magnitude data were taken from the Seismological Bulletin of Japan Meteorological Agency (JMA) during 19601976. (b) Cross sectional distribution of microearthquake foci in the same belt as in Fig. Ia from April, 1975 to Oct., 1976 (after TAKAGI et al., 1977). In insert, a schematical explanation of the seismicity and focal mechanism is shown (modified after YosHIr, 1978).

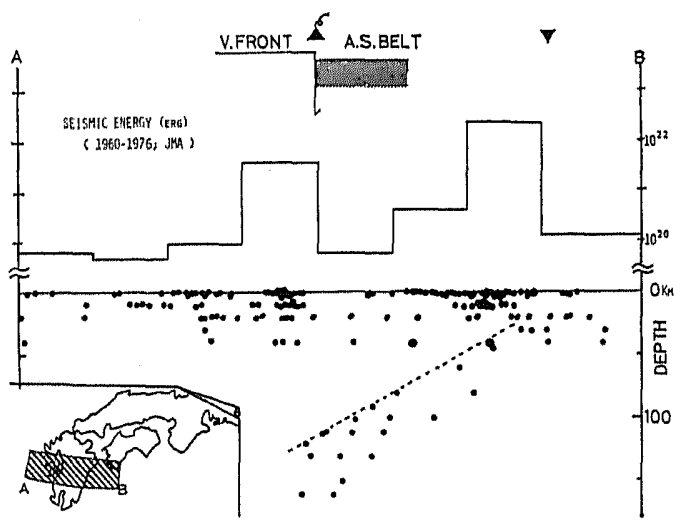

Fig. 2. Cross sectional distributions of released seismic energy (top) and earthquake foci (bottom) across the western part of Japan (Kyushu) based on the JMA data during 1960-1976. Data are taken from the hatched area in the insert.

The concentration of shallow earthquake foci into the $V_{b}=6.0 \mathrm{~km} / \mathrm{sec}$ layer is obvious at least beneath the land area. Shallow foci are distributed behind the volcanic front to the off coast of Japan Sea (hereafter called region C). Shallow seismic activity in the Japan Sea (off Oga peninsula) seems to be extended to the lower crust where the upper crust becomes thin. This may be related to the activity along eastern margin of the Japan Sea (Fukao and Furumoto, 1975).

Major seismic activity is found between the trench and "aseismic front" (hereafter called region A, "seismic prism"). This activity continued to the upper plane of the 
double-planed deep seismic zone (Hasegawa et al., 1978). The boundary between upper lithosphere and subducting Pacific plate is estimated and shown by a broken curve in Fig. 1b. $P_{n}$ velocity of this region $\mathrm{A}$ is $8.1 \mathrm{~km} / \mathrm{sec}$ and clearly contrasting with that of $7.5 \mathrm{~km} / \mathrm{sec}$ beneath the Japanese land area. The eastern boundary of this low $P_{n}$ region coincides with the aseismic front (REsearch Group for Explosion Seismology, 1977; YosHII, 1978). The scattered earthquake foci beneath the trench appear to extend to a depth of $100 \mathrm{~km}$. They may be the aftershocks of the great normal fault event off Sanriku (KANAMORI, 1971). But as the accuracy of hypocentral determination is relatively less in this region, there remains some possibilities of the biasing of hypocenters caused by the lateral heterogeneities in the velocity structure.

Principal stresses projected in this cross section are schematically indicated in the insert in Fig. $1 \mathrm{~b}$ after YosHII (1978). East-west compression (mostly thrust fault events) are observed for shallow earthquakes in both region A and C. As pointed out by YosHIr (1978), low-angle thrust fault events along the inferred upper surface of the descending lithosphere occur only ocean side of the aseismic front.

Temperature distribution across the northeastern Japan arc is estimated based on a model developed by HASEBE et al. (1970) which satisfies the observations of terrestrial heat flow taking into acount of the frictional heating along Wadati-Benioff zone below $60 \mathrm{~km}$ depth and penetrative convection heat transfer in the upper mantle wedge. To estimate the temperature at the upper-most mantle beneath region $\mathrm{C}$ (volcanic area), petrological model by TAKAHASHI (1978) is also referred to. In Fig. 3, the temperature and velocity structure for the three regions (A, B and C) are schematically indicated. Average values of terrestrial heat flow is shown in the upper diagram of Fig. 3 (after HASEBE et al., 1970).

Note that $500^{\circ} \mathrm{C}$ isotherm nearly coincides with the lower limit of intraplate shallow seismicity in region C. Temperatures at the depth of $10-20 \mathrm{~km}$ are more or less similar in region $\mathrm{C}$ and region $\mathrm{B}$, but are significantly lower in region $\mathrm{A}$. Nearly vertical isotherms for temperatures higher than $300^{\circ} \mathrm{C}$ are dominant feature in "seismic prism." Although precise location of vertical isotherms in this region would vary with model parameters, the high seismic activity could be closely related with the low temperature and low angle thrust fault along the subducting lithosphere.

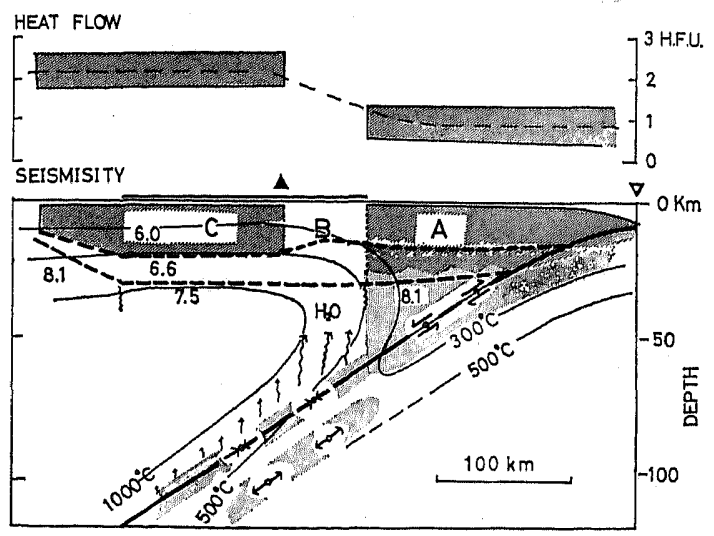

Fig. 3. Cross sectional diagrams of heat flow (top) and structure (bottom) beneath island arcs. Numerals in the bottom figure indicate the values of $V_{\phi}$ by Research Group for Exploston SeIsMology (1977). 


\section{Variation of Pore Pressure across Trench-Arc Systems}

There are many factors closely related to the observed variation in seismic activity across the trench-arc systems. Among them, followings are likely to be important; 1) the differences of strength due to different types of constituent material, 2) the differences of stress level due to interactions of subducting plate and/or flow law of the crustal rocks, and 3) the variation of effective pressure acting on pre-existing faults.

The first factor seems to be less important if we consider that shallow earthquakes are explained by stick-slip motion of pre-existing fault. STESKY et al. (1974) showed no difference existed in the boundary of stick-slip to stable-sliding transition between granite and gabbro, that are considered to be representative rock types of $6.0 \mathrm{~km} / \mathrm{sec}$ layer and $6.6 \mathrm{~km} / \mathrm{sec}$ layer respectively. It seems unlikely that this factor alone can explain both the low seismicity in region $\mathrm{B}$ and the depth-limit in region $\mathrm{C}$.

The second factor could be a likely source. As subducting slab causes a drag force along Wadati-Benioff zone and a tilting of overlying continental plate wedge toward the trench during interseismic period, local deviatric tensile stress region appears around volcanic front (Smith and Toksöz, 1972; Bischke, 1974; Neugebauer and Breitmayer, 1975). YAMASHINA et al. (1978) noted that the horizontal contractive strain perpendicular to the trench axis has a local minimum which coincides to aseismic belt (region B) based on a calculation to fit the observed crustal deformation in eastern Hokkaido by SHIMAzAKI (1974). The location and width of the local minimum in contractive horizontal strain depend on the depth and dip angle along which the drag force due to subducting slab is assumed (e.g., SENo, 1978). Since this local minimum becomes less clear with depth gradually, a sharpness of aseismic front throughout the crust and upper mantle and the concentration of seismicity in the upper crust in region $\mathrm{C}$ should need additional explanations.

KoBAyASHI (1976) discussed that the constituent material throughout the crust of Japan arc is likely to be granodioritic rocks and flow law of quartz could be applicable to explain the depth-limits of shallow intraplate seismicity. He assumed that the seismically active region corresponds to the region where a shear stress is higher than the critical value estimated from the flow law of granodioritic rocks (represented by quartz) at geological strain rate of $10^{-14} \mathrm{sec}^{-1}$. Combining the temperature distribution estimated from terrestrial heat flow and a critical shear stress of $\$ 100$ bars (i.e., similar to the stress drop from focal mechanism), he concluded that $300^{\circ} \mathrm{C}$ isotherm would correspond to the depth-limits of shallow intraplate seismicity. It would, however, be difficult to explain the existence of the aseismic belt when we consider the temperature distribution in the belt (Fig. 3).

As a consequence, we suggest that pore pressure in the crust would vary from trench to back arc, that is, the third factor may be responsible for the shallow seismic activity in the plate convergence area. Stick-slip and stable-sliding phenomena are controlled by temperature and effective pressure (confining pressure minus pore pressure) as shown by laboratory experiments on pre-existing faults (STESKY et al., 1974). If we consider that seismically active region corresponds to the region of stick-slip sliding, less active region of similar depth and temperature should have higher pore pressure. Left diagram in Fig. 4 shows stick-slip and stable-sliding regions in the temperature-effective pressure diagram after STESky et al. (1974) and BRACE (1977). Dashed curve with hatches indicates the 


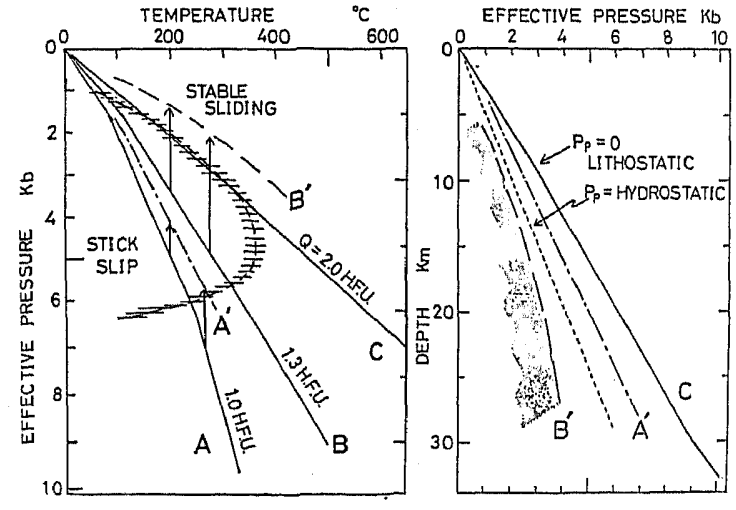

Fig. 4. In the left, stick-slip to stablesliding transition boundary (a dashed curve with hatches) is shown in the temperature-effective pressure diagram (after STESKY et al., 1974). Solid lines labelled $\mathrm{A}, \mathrm{B}$ and $\mathrm{C}$ indicate representative geotherms corresponding to the regions in Fig. 3. Surface heat flow, Q (1H.F.U. $=10^{-6} \mathrm{cal} / \mathrm{sec} \cdot \mathrm{cm}^{2}$ ), for each region is also indicated, in which depth scale to the right should be referred to when pore pressure is zero. Since the high pore pressure makes the effective pressure low, the geotherms move upward as indicated by arrows (lines $A^{\prime}$ and $B^{\prime}$ ). In the right diagram, effective pressure versus depth is shown for various pore pressures (see text).

boundary of stick-slip to stable-sliding transition, and should be regarded as an iso-stress drop curve (experimentally zero stress drop). Depths in the righthand side correspond to the case of zero pore pressure. Solid lines labelled $A, B$ and $C$ show representative temperature distributions within the crust in respective regions estimated from heat flow and appropriate heat generation in the crust. A representative surface heat flow $(Q)$ in each region is also indicated.

If we assume laboratory determined stick-slip to stable-sliding transition actually corresponds to seismically active to inactive boundary, effective pressure in the regions $A$ and $B$ should be lowered to the lines of $A^{\prime}$ and $B^{\prime}$, respectively, as shown by arrows in the left diagram in Fig. 4. To the right in Fig. 4, effective pressure with depth thus expected is indicated for each region. The curves with pore pressure $\left(P_{P}\right)$ equal to zero and to the hydrostatic pressure are also shown by solid and dotted lines. Judging from this figure, we can estimate that the pore pressure is highest in region $\mathrm{B}$ (aseismic belt) and lowest in region C. It may be expected that $P_{P}$ is nearly hydrostatic or the ratio of $P_{P}$ to total pressure $\left(P_{t}\right)$ ranges 0.1 to 0.5 in region $A$, and $P_{P} \mid P_{t} \geq 0.5$ and $\leqslant 0.2$ for regions $\mathrm{B}$ and $\mathrm{C}$ respectively.

However, as already pointed out by Brace (1972) and Stesky and BraCe (1973), many difficulties and uncertainties still exist to apply above assumptions to the actual earthquakes. For example, experimentally determined frictional shear stress and stress drop are higher than those of actual earthquakes (STESKY and BRACE, 1973), acoustic emission is observed even in stable-sliding region (i.e., STESKx, 1975), and fault gauge in actual fault surface in the earth could have influenced on the stick-slip to stable sliding transition boundary (BRACE, 1977).

Although the existence of precise correspondence between the stick-slip phenomenon observed in laboratory experiments and earthquakes is a fundamental problem to be investigated more extensively, our explanation and conclusion would not be affected so much at least in a relative and qualitative sense.

A high seismicity in the upper mantle beneath the seismic wedge could be understood following the idea similar to that of KoBAYAshr (1976). If we consider that mantle is composed of peridotitic rocks, flow law of olivine could be applied to estimate the shear stress. Using the values both for wet and dry olivines with strain rate of $10^{-14} \mathrm{sec}^{-1}$ (KIRBY, 1977), the estimated shear stress in the upper mantle at the aseismic front (Fig. 3) 
is about a few $\mathrm{kb}$ and 100 bars for the isotherms of $500^{\circ} \mathrm{C}$ and $750^{\circ} \mathrm{C}$, respectively. Below this temperature, that is, from the aseismic front toward the trench, shear stress becomes high and rocks would become brittle. Aseismic front could be understood this way as far as the upper mantle is concerned.

\section{Discussion}

At present we have no direct evidence of pore pressure differences in the upper crust of depths 5-20 km. As pointed out by STESKY et al. (1974), a high pore pressure region is observed in deep drill holes in California Coast Range and this region seems to correspond to the relatively low seismicity area (BERRY, 1973). The region B (aseismic belt) where we expect relatively high pore pressures, corresponds to non-volcanic frontal arc characterized by high gravity anomaly (YosHm, 1978) and gradual uplift since Tertiary (e.g., Sugrmura and UYEDA, 1973). To keep pore pressure high, e.g., higher than hydrostatic, it may need the supply of fluid from below and a low permeable cap rock as known in the geothermal field. Although it is generally or implicitly considered that there would be much of water (and high fluid pressure) in volcanic region (region C) relative to region $\mathrm{B}$ (K. Nakamura, personal communication, 1977), it deos not always mean that the pore pressure is high when minerals are partially hydrated.

The current petrological view of volcanism of island arcs (e.g., RinGwood, 1977) suggests free water released from the subducting slab by dehydration and its interaction with the overlying mantle wedge have great influence of volcanic activity. If we consider the overlying mantle wedge to be peridotitic and in the water-saturated condition $\left(P_{\mathrm{H}_{2} \mathrm{O}}=\right.$ $P_{t}$ ), the stability field of the hydrated minerals could be estimated provided that the subducting oceanic crust is hydrous basalt and gabbro and temperature distribution in the wedge is known (Delany and Helgeson, 1978). Figure 5 shows schematically the mineral stability boundaries for two cases of temperature distributions. We expect that partial melting zone beneath volcanic area (region $C$ ) would not extend toward the trench so much and the temperature beneath the frontal arc (region B) would be lower than $1,000^{\circ} \mathrm{C}$. Thus, released free water from the subducting oceanic crust could make melt beneath region $C$, but not beneath region $B$. As the thermal regime is so complex in this mantle wedge, there could still be two possible cases, 1) no hydrous minerals and 2) talc and presumably chrysotile exist beneath region B. The former (top in Fig. 5) expects that the aseismic front nearly coincides with $750^{\circ} \mathrm{C}$ isotherm and released water would rise freely through the mantle. The latter (bottom in Fig. 5) expects that the temperature of the aseismic front is $500^{\circ} \mathrm{C}$ or less. As pointed out by Delany and Helgeson (1978), the release of water through the dehydration of subducting oceanic crust should be controlled by the rate of heat supply from the ambient mantle or heat generated in this portion such as viscous frictional heating. Although we could not, at the moment, specify the precise depth of complete dehydration reaction in the subducting slab, most probable depth would be some 60 to $100 \mathrm{~km}$ in the northeastern Japan when dip angle of subducting plate is about $30^{\circ}$ as pointed out by HASEBE et al. (1970). It is interesting to note that the aseismic front meets the plate-interface at about $60 \mathrm{~km}$ depth and earthquakes with low angle thrust fault mechanism occur only above this depth (Yosmrr, 1978).

The newly released water will be highly mobile because the migration of free water would be controlled by permeable flow due to buoyancy effect as suggested by ANDERSON et al. (1978). Then we could expect that a large volume of released water would migrate 


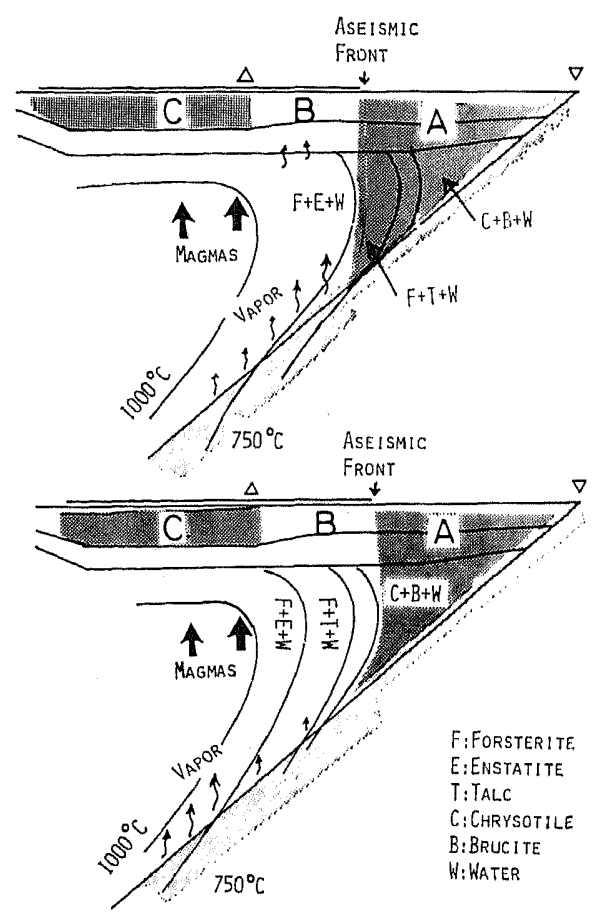

Fig. 5. Mineral stability boundaries for periclotitic mantle in the 'wedge-zone' beneath the arc-trench gap are schematically shown in two cases, when hydrous minerals are unstable (top) and stable (bottom) beneath aseismic belt (region B). Shaded areas indicate seismically active regions as in Fig. $1 \mathrm{~b}$.

through the upper mantle beneath region $B$, and the lower crust of this region would be saturated with water.

As noted in the previous section, the observation that $P_{n}$ velocity of $8.1 \mathrm{~km} / \mathrm{sec}$ in the seismic wedge at $30 \mathrm{~km}$ depth seems to be incompatible with wet peridotitic mantle model. As far as the water-saturated or hydrous mantle candidate minerals are concerned, $V_{p}=$ $8.1 \mathrm{~km} / \mathrm{sec}$ could not be explained from experiments. There may be a possibility that released free water could not reach the apex of the mantle wedge beneath the seismic wedge, and this region may be dry and non-hydrous, although we need to explain the generation of blue-schist and greenschist facies metamorphic rocks and serpentinite.

In summary, though no direct evidence for high pore pressure in region $B$ can be demonstrated and no quantitative correspondence between stick-slip phenomenon and shallow seismicity, the migration of released water from subducting oceanic crust would have an important role in the mantle wedge and lower crust.

Our conclusion could be tested by 1) precise determination of stress drop variation with depth or across region $\mathrm{B}, 2$ ) more investigation of fine crustal velocity structure, 3) deep drilling in respective region to estimate average pore pressure, and 4) the investigation of thermal regime in the wedge beneath arc-trench gap taking into acount of dynamical processes and influence of fluid phases.

We thank A. Takagi, A. Hasegawa, T. Yoshii, T. Seno and R.N. Anderson for discussions and access to unpublished manuscripts. Critical comments by K. Nakamura, S. Uyeda, T. Hirasawa and Y. Kobayashi were helpful.

We wish to thank T. Asada and A. Takagi for their kind encouragements and to $H$. Wada for typing the manuscript. 


\section{REFERENCES}

Anderson, R.N., S. Uyeda, and A. Mryashrro, Geophysical and geochemical constraints at converging plate boundaries. Pt. I; Dehydration in the down going slab, Geophys. J. R. Astr. Soc., 44, 333-357, 1976.

Anderson, R.N., S.E. Delong, and W.M. Schwarz, Geophysical and geochemical constraints at converging plate boundaries. Pt. II; A thermal model for subduction with dehydration in the down going slab, Tectonophysics, 1978 (in press).

BerRy, F.A.F., High fluid potentials in California Coast Ranges and their tectonic significance, Bull. Am. Assoc. Pet. Geol., 57, 1219-1248, 1973.

Brschke, R.E., A model of convergent plate margins based on the recent tectonics of Shikoku, Japan, $J$. Geophys. Res., 79, 4845-4857, 1974.

BRACE, W.F., Laboratory studies of stick-slip and their application to earthquakes, Tectonophysics, 14, 189-200, 1972.

BRACE, W.F., Recent laboratory studies of earthquake mechanics and prediction. J. Phys. Earth, 25, Suppl., S185-S202, 1977.

BraCE, W.F. and J.D. BYerlee, California earthquakes: Why only shallow focus? Science, 168, 1573-1575, 1970.

Byerlee, J.D. and W.F. Brace, High-pressure mechanical instability in rocks, Science, 164, 713-715, 1969.

Delany, J.M. and H.C. Helgeson, Calculation of the thermodynamic consequences of dehydration in subducting oceanic crust to $100 \mathrm{~kb}$ and $800^{\circ} \mathrm{C}, \mathrm{Am} . J$. Sci., 278, 638-686, 1978.

ENGDAfil, E.R. and C.H. Scholz, A double Benioff zone beneath the central Aleutians; An unbending of the lithosphere, Geophys. Res. Lett., 4, 473-476, 1977.

Fukao, Y. and M. Furumoto, Mechanism of large earthquakes along the eastern margin of the Japan Sea, Tectonophysics, 25, 247-266, 1975.

HASEbe, K., N. Fujir, and S. Uyeda, Thermal processes under island arcs, Tectonophysics, 10, 335--355, 1970.

Hasegawa, A., N. Umino, and A. TAKagr, Double-planed structure of the deep seismic zone in the northeastern Japan arc, Tectonophysics, 47, 43-58, 1978.

Kanamori, H., Seismological evidence for a lithospheric normal faulting-The Sanriku earthquake of 1933, Phys. Earth Planet. Inter., 6, 346-359, 1971.

Karig, D.E., Evolution of arc systems in the western Pacific, Ann. Rev. Earth Planet. Sci., 2, 51-75, 1974.

Karig, D.E. and G.F. Sharman, III, Subduction and accretion in trenches, Geol. Soc. Am., 86, 377-389, 1975.

KIRBY, S.H., State of stress in the lithosphere: Inferences from the flow laws of olivine, Pageoph, 115, 245-258, 1977.

Kobayashi, Y., A relationship between the clistribution of focal depth of microearthquakes and surface heat flow in the southwestern Japan and central Japan, in Proceedings of Symposium on Earthquake Prediction in Japan, Seismol. Soc. Jpn., pp. 184-193, 1976 (in Japanese with English abstract).

Mogr, K., Regional variation of aftershock activity, Bull. Earthq. Res. Inst., 45, 711-726, 1967.

Neugebauer, H.J. and G. Brextmayer, Dominant creep mechanism and descending lithosphere, Geophys. J.R. Astr. Soc., 43, 873-895, 1975.

Orke, K., Seismic activities and crustal movements at the Yamasaki fault and surrounding regions in the southwest Japan, J. Phys. Earth, 25, Suppl. S31-S41, 1977.

OxBurgh, E.R. and D.L. TurcotTe, The physico-chemical behavior of the descending lithosphere, Tectonophysics, 32, 107-128, 1976.

Research Group for Explosion SeIsmology, Regionality of upper mantle around northeastern Japan as derived from explosion seismic observations and its seismological implications, Tectonophysics, 37, 117-130, 1977.

Ringwoon, A.E., The petrological evolution of island arc systems, J. Geol. Soc. Lond., 130, 183-204, 1974.

Ringwood, A.E., Petrogenesis in island arc systems, in Island Arcs, Deep Sea Trenches and Back-Arc Basins, edited by M. Talwani and W.C. Pitman, III, pp. 311-324, Am. Geophys. Union, 1977.

Seno, T., Intraplate seismicity in Tohoku and Hokkaido, northern Japan, and a possibility of a large interplate earthquake off the southern Sanriku coast, J. Phys. Earth., 1978 (in press).

Shimazaki, K., Pre-seismic crustal deformation caused by an under thrusting oceanic plate, in eastern Hokkaido, Japan, Phys. Earth Planet. Inter., 8, 148-157, 1974.

Smith, A.T. and M.N. Tosoz, Stress distribution beneath island arcs, Geophys. J. R. Astr. Soc., 29, 289-318, 1972.

STESky, R.M. and W.F. BRACE, Estimation of frictional stress on the San Andreas fault from laboratory measurements, in Proceedings of the Conference on Tectonic Problems of the San Andreas Fault System, edited by R.L. Kovach and A. Nur, pp. 206-214, Stanford Univ. Publ., Stanford, Calif., 1973.

Steskx, R.M., Acoustic emission during high temperature frictional sliding, Pageoph, 113, 31-43, 1975. 
Stesky, R.M., W.F. BRACE, D.K. RILeY, and P.Y.F. Robin, Friction in faulted rock at high temperature and pressure, Tectonophysics, 23, 177-203, 1974.

Sugrmura, A. and S. UYEDA, Island Arcs; Japan and Its Environs, 247 pp. Elsevier, New York, 1973.

Takagr, A., A. Hasegawa, and N. Umino, Seismic activity in the northeastern Japan arc, J. Phys. Earth, 25, Suppl., S95-S104, 1977.

Takahashr, E., Petrological model of the upper mantle and the lower crust of the island arc: Petrology of mafic and ultra-mafic xenoliths in Cenozoic alkali basalts of the Oki-dogo island in the Japan Sea, in Physics and Chemistry of Magma Genesis (Bull. Volcanol., Special issue), 1978 (in press).

TsumurA, K., Microearthquake activity in the Kanto District, Publications for the 50th Anniversary of the great Kanto Earthquake in 1923, pp. 63-87, 1973 (in Japanese with English abstract).

UmINo, N. and A. HASEGAWA, On the two-layered structure of deep seismic plane in northeastern Japan arc, Zisin 2, 28, 125-139, 1975 (in Japanese with English abstract).

Yamashina, K., K. Shimazakr, and T. Kato, Aseismic belt along the frontal arc and plate subduction in Japan, J. Phys. Earth, this issue, S 447-S 458, 1978.

Yosmir, T., Proposal of the "aseismic front," Zisin 2, 28, 365-367, 1975 (in Japanese).

Yosmin, T., A detailed cross-section of the deep seismic zone beneath northeastern Honshu, Japan, Tectonophysics, 1978 (in press).

Yoshil, T. and S. Asano, Time-term analysis of explosion seismic data, J. Phys. Earth, 20, 47-57, 1972. 